\section{Kidney Blood Pressure Research}

\title{
Sonographic Image of Solitary Kidney in Wilms Tumour Survivors
}

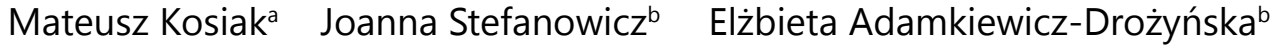 \\ Anna Balcerska $^{b} \quad$ Andrzej Kurylak $^{c}$ Ewa Demidowicz ${ }^{d}$
}

${ }^{a}$ Department of Family Medicine. Medical University of Gdansk, Gdansk, ${ }^{b}$ Department of Paediatrics, Haematology and Oncology. Medical University of Gdansk, Gdansk, cPaediatric Nursing Centre. Ludwik Rydygier Collegium Medicum in Bydgoszcz, Nicolaus Copernicus University in Torun, Torun, dDepartment of Paediatrics, Haematology and Oncology. Ludwik Rydygier Collegium Medicum in Bydgoszcz, Nicolaus Copernicus University in Torun, Torun, Poland

\section{Key Words}

Wilms tumour • Survivors • Solitary kidney • Sonography $・$ Renal function • Chronic kidney disease

\begin{abstract}
Background/Aims: This study presents an analysis of the sonographic and laboratory parameters of solitary kidney in Wilms tumour survivors (TWs) and compares these parameters with those of healthy individuals. Methods: Fifty-three TWs who completed treatment for Wilms tumour and 44 healthy individuals were enrolled. The study protocol consisted of completing a medical history, sonographic examination of the solitary kidney, estimation of glomerular filtration rate (eGFR) by the Schwartz or MDRD formulas, albumin urine excretion and BP measurement. Results: Sonographic signs of kidney damage were observed in 22 $(41,5 \%)$ TWs. The most frequently detected abnormalities are hyperechoic rings around renal pyramids ( $28,3 \% \mathrm{TWs}$ ). Hypertrophy of the solitary kidney occurred in $71,7 \%$ of cases. The mean volume of the solitary kidney was $77 \%$ of the sum of the two kidney volumes in the control group. The median eGFR in the TWs group was 117 with 25Q-105,5, 75Q-130 ml/min/1,73 $\mathrm{m}^{2}$ vs 131,8 with $25 \mathrm{Q}-124,75 \mathrm{Q}-140 \mathrm{ml} / \mathrm{min} / 1,73 \mathrm{~m}^{2}$ in the control group $(\mathrm{p}=0,000)$. Six TWs $(11,3 \%)$ had a value of eGFR below $90 \mathrm{ml} / \mathrm{min} / 1,73 \mathrm{~m}^{2}$. Increased urine albumin excretion (> $30 \mathrm{mg} / \mathrm{g}$ ) was observed in 7 TWs $(13,2 \%)$ and in $3(6,8 \%)$ individuals in the control group. Conclusion: Ultrasonographic abnormalities in solitary kidney of TWs are frequent. The most frequently detected abnormalities are hyperechoic rings around renal pyramids. Sonographic examination of TWs ought to be performed not only to detect tumour recurrence but also to assess the signs of kidney damage and their progression.

M. Kosiak and J. Stefanowicz contributed equally to this work.

\begin{tabular}{ll}
\hline Joanna Stefanowicz, MD, PhD & Department of Paediatrics, Haematology and Oncology, Medical University of Gdansk, \\
& 7 Debinki Street, 80-952 Gdansk (Poland) \\
& Tel. +48 5834928 80, Fax +48 5834928 47, E-Mail jstefanowicz@gumed.edu.pl
\end{tabular}
\end{abstract}




\section{Kidney Blood Pressure Research}

Kosiak et al.: Sonographic Image of Solitary Kidney in TWs

\section{Introduction}

Wilms tumour (TW) is the most common neoplasm of kidney in children [1, 2]. The results of treatment of TW have improved in recent years, reaching 4-year overall survival in the favourable histology group of nearly $90 \%$. The number of children who complete the treatment and survive is increasing [2]. According to the International Society of Paediatric Oncology (Societe Internationale D'Oncologie Pediatrique - SIOP), ultrasound examination ought to be performed five to eight times during first five years after treatment in single kidney disease without metastases [3]. The early detection of tumour recurrence or metachronous nephroblastoma in the solitary kidney is the main purpose for this examination [4]. In addition, ultrasound examination provides an opportunity to assess the signs of kidney damage. The signs of kidney damage in ultrasound examination are among the diagnostic criteria for chronic kidney disease (CKD) [5]. According to the National Kidney Foundation (NKF), CKD is defined as either kidney damage or estimated glomerular filtration rate (eGFR) below $60 \mathrm{ml} / \mathrm{min} / 1.73 \mathrm{~m}^{2}$ for more than 3 months [5]. Kidney damage is defined as pathological abnormalities or markers of damage, including abnormalities in blood or urine tests or in imaging studies [5, 6]. The Kidney Disease, Improving Global Outcomes (KDIGO) recommendations from 2012 define CKD as abnormalities of kidney structure or function, present for $>3$ months with implications for health [6]. Signs of kidney damage may indicate the risk of deterioration of kidney function in the future [5]. Wilms tumour survivors (TWs) are at risk of deteriorating renal function and CKD because of the following: decreased number of nephrons after nephrectomy, nephrotoxic side effects of chemotherapeutic agents (carboplatin, cisplatin, ifosphamide, cyclophosphamide) or radiation therapy if the solitary kidney was in the field of radiation $[7,8]$.

The function of the solitary kidney in TWs has been analysed in several studies. Some of those studies focused on hypertrophy of the solitary kidney $[9,10,11,12,13,14]$. A few recent publications provided insight into the sonographic features of the kidney, underlining the need for detailed analysis $[15,16]$. To date, sonographic images of the solitary kidney in prospective studies with control groups have not yet been reported.

The aim of this study was to present the characteristics of sonographic images of solitary kidney in TWs and to compare those characteristics with those of healthy individuals. The second aim of the study was to assess renal function based on estimated glomerular filtration rate (eGFR), urine albumin excretion and urine sediment analysis.

\section{Materials and Methods}

This was a cross-sectional prospective study with a control group of healthy individuals.

\section{Patients}

Fifty-three individuals (27 females and 26 males) who had undergone nephrectomy and treatment for TW in the Department of Paediatrics, Haematology and Oncology at the Medical University of Gdansk or in the Department of Paediatrics, Haematology and Oncology, Ludwik Rydygier Collegium Medicum in Bydgoszcz, Nicolaus Copernicus University in Torun, were enrolled.

Patients were excluded from the study if they had one of the following: heminephrectomy on medical history, bilateral TW, congenital abnormality of the solitary kidney or the urinary tract, urinary tract infection at the time of study, tumour recurrence or secondary neoplasm.

Forty-four healthy individuals (20 females and 24 males) were enrolled as the control group. They did not significantly differ from the TW group in terms of age, height, BMI (body mass index) and gender distribution. Individuals were excluded from the group if they had one of the following: medical record of any kidney disease, congenital abnormality of the solitary kidney or urinary tract or infectious disease at the time of the study. A comparison of the TWs and control groups is presented in Table 1. 


\section{Kidney Blood Pressure Research}

Methods

The study protocol consisted of completing a medical history, physical examination, sonographic evaluation of the solitary kidney, laboratory tests and blood pressure assessment.

\section{Ultrasound examination}

All ultrasound examinations were performed by the same person (M.K.) in the Department of Paediatric \& Adolescent Nephrology \& Hypertension Medical University of Gdansk, Poland; in the Department of Paediatrics, Haematology and Oncology, Medical University of Gdansk, Poland; or in the Department of Paediatrics, Haematology and Oncology Ludwik Rydygier Collegium Medicum in Bydgoszcz. Nicolaus Copernicus University in Torun.

The following equipment was used: GE Logiq 500, GE Logiq E and GE Logiq 7 (GE Medical Systems, Waukesha, WI, USA) with convex 3, 5-5, 0 MHz and linear 8, 0-12, 0 probes.

Kidneys were examined in the prone position. Lumbar muscles were used as acoustic windows. The examination conditions were the same for every patient. All patients were asked not to drink any fluids one hour before the examination.

The following sonographic image features were considered: medullo-cortex differentiation, increased echogenicity of renal cortex, scars, hyperechoic rings around pyramids, cysts and calculi.

All individuals had the following parameters of the solitary kidney measured: length, width, depth, volume and parenchymal thickness of the kidney, and length and width of the central echo of the kidney. For the purposes of this study, length of kidney was reported as the percentage of expected length of the normal kidney. This was defined as the kidney length on sonographic examination as a percentage of the hypothetical kidney length that the child would be expected to have if he or she had not undergone nephrectomy. Values of the hypothetical, expected length of kidney were based on Chen et al. using an internet calculator - Mr. Nomogram $[17,18]$. Based on obtained data, the following indices were calculated: kidney length/height; parenchymal thickness/kidney length; and length of central echo/length of kidney.

Blood flow in each kidney was assessed using spectral Doppler and colour Doppler options. The resistance index (RI) was evaluated for every patient: RI = (Vmax - Vmin) / Vmax). In each measurement, the value of the insonation angle was under 60.

\section{Laboratory tests}

All laboratory tests were performed in the Central Laboratory of the Medical University of Gdansk.

Creatinine serum concentrations were assessed using the colorimetric-modified Jaffe method (mg/ dL) (Architect c8000).

eGFR in individuals under 18 years of age was estimated with the Schwartz formula: eGFR [ml/min/1, $\left.73 \mathrm{~m}^{2}\right]=\mathrm{k} x$ height $[\mathrm{cm}] /$ serum creatinine concentration $[\mathrm{mg} / \mathrm{dl}]$, where the constant $\mathrm{k}$ was defined using published literature values: $\mathrm{k}=0,55$ for children aged 2-12 or adolescent females, and $\mathrm{k}=0,7$ for adolescent males [19]. In individuals over 18 years of age, GFR was estimated with the MDRD formula: eGFR [ml/ $\left.\min / 1,73 \mathrm{~m}^{2}\right]=170 \times$ (serum creatinine concentration $\left.[\mathrm{mg} / \mathrm{dL}]\right)^{-0,176} \times($ serum concentration of blood urea nitrogen $[\mathrm{mg} / \mathrm{dL}])^{-0,170} \times$ (albumin serum concentration $\left.[\mathrm{g} / \mathrm{dL}]\right)^{0,318} \times 0,762$ (for women) $\times 1,180$ (for African Americans) [20].

Albumin urine excretion was measured in urine spot samples using the immunologic method, Multigent, from Abbott Laboratories (Wesbaden, Germany). Increased excretion of albumin with urine was defined as a urine albumin to creatinine ratio (ACR) of over $30 \mathrm{mg} / \mathrm{g}$ [21].
Table 1. Comparison of TWs group and control group. TWs- Wilms mean and standard deviation were presented. ** For variables without a normal distribution the median, 25Q, 75Q were presented

\begin{tabular}{lccc}
\hline Parameter & $\begin{array}{c}\text { TWs group } \\
\mathrm{n}=53\end{array}$ & $\begin{array}{c}\text { Control group } \\
\mathrm{n}=44\end{array}$ & $\mathrm{p}$ \\
\hline age [years] & $12,6 \pm 5,6^{*}$ & $11,3 \pm 4,9^{*}$ & 0,245 \\
height [cm] & $149,2 \pm 22,1^{*}$ & $146,5 \pm 26,9^{*}$ & 0,588 \\
weight [kg] & $42,5 \pm 17,7^{*}$ & $44,1 \pm 20^{*}$ & 0,685 \\
Sex [F/M] & $27 / 26$ & $20 / 24$ & 0,590 \\
age at time of diagnosis [years] & $2,9(1,7 \div 4,3)^{* *}$ & - & - \\
time from the end of treatment [years] & $8,5 \pm 5,7^{*}$ & - & - \\
\hline
\end{tabular}




\section{Kidney Blood Pressure Research}

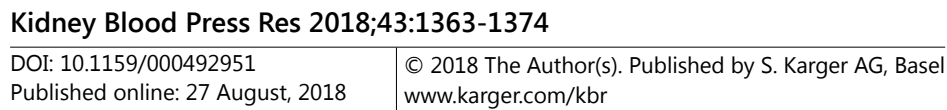

Kosiak et al.: Sonographic Image of Solitary Kidney in TWs

Blood pressure

Blood pressure was assessed in all individuals in the TWs and control groups with the Dinamap DPC 120 X-EN GE. Each individual had blood pressure measured three times according to the guidelines of The Fourth Report on the Diagnosis, Evaluation and Treatment of High Blood Pressure in Children and Adolescents [22].

\section{Statistical analysis}

Statistical analysis was performed using Statistica 8.0 PL software (Polish version; StatSoft, Tulsa, OK, USA). A normal distribution of the data was verified using the Shapiro-Wilk W-test. Statistical significance between different groups was calculated by one-way analysis of variance (ANOVA), alternatively using the U Mann-Whitney test when the variances in groups were not homogeneous (the homogeneity of variance was determined by the Levene test). Statistical significance between frequencies was calculated by the chi-square test with Yate's correction or Fisher exact test. A correlation analysis was performed using Spearman's methods. The level of significance was set at $\mathrm{p}<0,05$.

Ethics Approval

This study was approved by the Independent Bioethical Committee of Scientific Researchers at the Medical University of Gdansk. Written informed consent was obtained from the legal guardians of the children.

\section{Results}

\section{Signs of kidney damage on USG}

Signs of kidney damage on sonographic examination in the TW group were observed in 22 individuals $(41,5 \%)$. These findings are presented in Table 2 . The most frequently detected abnormalities were hyperechoic rings around renal pyramids (Fig. 1). Six TWs (11, $3 \%$ ) had two abnormalities on sonographic examination. None of individuals in the TWs group had three or more abnormalities.

Hypertrophy of solitary kidney was defined when length of kidney exceeded over value of $95^{\text {th }}$ centile according to height, gender and race. The length of the solitary kidney in thirtyeight $(71,7 \%)$ TWs exceeded the value of the $95^{\text {th }}$ percentile, according to height, gender and race.

Mean volume of kidney in TWs group was 77\% of a mean sum of two kidneys volume in the control group $(\mathrm{p}=0,0034)$. A comparison of the sonographic measurements between the TWs and control groups is presented in Table 3.

No differences were observed between the groups in terms of the side of the kidney.

There were correlations in the TWs group between the percent of expected renal length and the following parameters: age $(p=0,0006)$ and height $(p=0,0022)$.

There were no correlations in the TWs group between percent of expected renal length and following parameters: age at time of diagnosis, time from nephrectomy, and eGFR ( $p>0$, 05).

There was no significant difference between the TWs and control groups in terms of RI, $p=0,93$. The mean values of RI over 0 , 65 were detected in seven TWs and in one person in the control group. None of the individuals had mean values of RI over 0,7 .

In 22 TWs with abnormalities

Table 2. Abnormalities in sonographic examination In TWs and control group. TWs - Wilms tumour survivors

\begin{tabular}{lccc}
\hline Signs of kidney damage in sonographic examination & $\begin{array}{c}\text { TWs group } \\
\text { number of individuals }\end{array}$ & $\begin{array}{c}\text { Control group } \\
\text { number of individuals }\end{array}$ & $\mathrm{p}$ \\
\hline hyperechoic rings around renal pyramids & 15 & 4 & $0,034^{*}$ \\
increased echogenicity of renal cortex & 6 & 0 & $0,030^{*}$ \\
scars & 4 & 0 & 0,124 \\
calculi & 3 & 0 & 0,249 \\
cysts & 1 & 0 & 0,999 \\
diffused medullo-cortex differentiation & 0 & 0 & - \\
\hline
\end{tabular}




\section{Kidney Blood Pressure Research}

on sonographic examination, five also had abnormalities in laboratory tests: in three cases, there was decreased eGFR below $90 \mathrm{ml} / \mathrm{min} / 1,73$ $\mathrm{m}^{2}$ without increased albumin excretion; in one person, there was decreased eGFR below 90 $\mathrm{ml} / \mathrm{min} / 1,73 \mathrm{~m}^{2}$ with increased albumin excretion (ACR >30 $\mathrm{mg} / \mathrm{g}$ ); and in one person, there was increased albumin excretion (ACR > $30 \mathrm{mg} / \mathrm{g}$ ) with normal eGFR.

\section{eGFR}

Mean eGFR was statistically lower in the TWs than in the control group: 117 (25Q-106; $75 \mathrm{Q}-130) \mathrm{ml} / \mathrm{min} / 1,73 \mathrm{~m}^{2}$ vs 131,8 (25Q-124; 75Q-140) $\mathrm{ml} / \mathrm{min} / 1,73 \mathrm{~m}^{2}(\mathrm{p}=0,000)$. Six TWs $(11,3 \%)$ had values of eGFR below $90 \mathrm{ml} / \mathrm{min} / 1,73$ $\mathrm{m}^{2}$. None of the individuals in the control group had decreased eGFR below $90 \mathrm{ml} / \mathrm{min} / 1,73$ $\mathrm{m}^{2}$.

\section{Urine albumin excretion}

Increased urine albumin excretion (ACR > $30 \mathrm{mg} / \mathrm{g}$ ) was observed in 7 TWs $(13,2 \%)$ and in $3(6,8 \%)$ individuals in the control group. There was no significant difference in terms of mean ACR between the groups $(p=0,37)$. In two of these seven

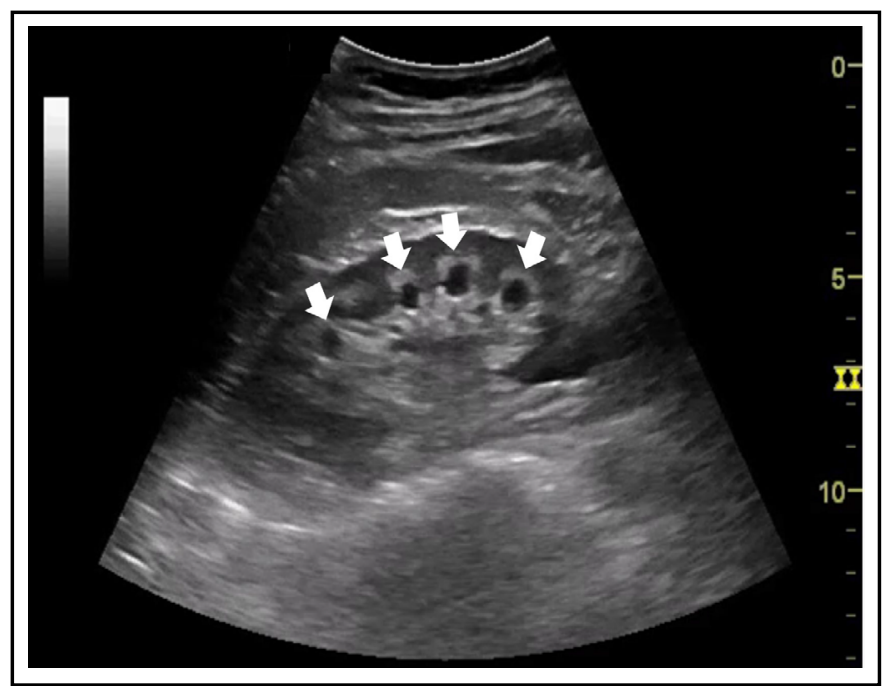

Fig. 1. Hyperechoic rings around renal pyramids.

Table 3. Comparison of sonographic measurements between TWs group and control group. TWs- Wilms tumour survivors. LK- left kidney; RK - right kidney; $\mathrm{p}$ - level of significance; RI - resistance index; *For variables with a normal distribution, the mean and standard deviation were presented. ${ }^{* *}$ For variables without a normal distribution the median, 25Q 75Q were presented

\begin{tabular}{lcccc}
\hline Parameter & Side & $\begin{array}{c}\text { TWs group } \\
\text { LK n }=22 \mathrm{RK} \mathrm{n}=31\end{array}$ & $\begin{array}{c}\text { Control group } \\
\mathrm{n}=44\end{array}$ & $\mathrm{p}$ \\
\hline length of kidney $[\mathrm{mm}]$ & left & $112(96 \div 124)^{* *}$ & $98(84 \div 105)^{* *}$ & 0,0010 \\
& right & $116 \pm 14,8^{*}$ & $93,8 \pm 14,0^{*}$ & 0,0000 \\
\% expected renal length & left & $115,2(111,1 \div 122,5)^{* *}$ & $101,8(81,4 \div 108,3)^{*}$ & 0,0000 \\
& right & $122,5(116,8 \div 127,6)^{* *}$ & $98,3(94 \div 102,6)^{* *}$ & 0,0000 \\
volume of kidney [m] & left & $138,6(78,9 \div 182,2)^{* *}$ & $88,2(62,5 \div 110,6)^{* *}$ & 0,0026 \\
& right & $129,4(106,2 \div 180,6)^{* *}$ & $90,6(58,7 \div 112,6)^{* *}$ & 0,0002 \\
parenchyma thickness [mm] & left & $12,9 \pm 2,8^{*}$ & $13,6 \pm 2,2^{*}$ & 0,3210 \\
& right & $14,3 \pm 2,9^{*}$ & $13,7 \pm 2,0^{*}$ & 0,2900 \\
length of central echo $[\mathrm{mm}]$ & left & $79,1 \pm 11,7^{*}$ & $69,4 \pm 11,6^{*}$ & 0,0027 \\
& right & $80,6 \pm 12,7^{*}$ & $67,2 \pm 14,9^{*}$ & 0,0002 \\
length of kidney / heigth & left & $0,076 \pm 0,008^{*}$ & $0,066 \pm 0,006^{*}$ & 0,0002 \\
& right & $0,077 \pm 0,007^{*}$ & $0,065 \pm 0,005^{*}$ & 0,0000 \\
parenchyma thickness / length of kidney & left & $0,12(0,1 \div 0,12)^{* *}$ & $0,09(0,09 \div 0,1) * *$ & 0,0000 \\
& right & $0,11(0,09 \div 0,12)^{* *}$ & $0,09(0,09 \div 0,1)^{* *}$ & 0,0070 \\
length of central echo / length of kidney & left & $0,698(0,686 \div 0,716)^{* *}$ & $0,733(0,701 \div 0,755)^{* *}$ & 0,04470 \\
& right & $0,696(0,662 \div 0,0727)^{* *}$ & $0,728(0,703 \div 0,764)^{* *}$ & 0,0039 \\
RI & & $0,58(0,55 \div 0,63)^{* *}$ & $0,59(0,57 \div 0,61)$ & 0,93 \\
\hline
\end{tabular}
also observed: one person had decreased eGFR $\left(88,4 \mathrm{ml} / \mathrm{min} / 1,73 \mathrm{~m}^{2}\right)$ and signs of kidney damage on USG (hyperechoic rings around renal pyramids, calculi); one person had increased creatinine concentration ( 0 , $91 \mathrm{mg} / \mathrm{dl}$ ) and signs of kidney damage on USG (hyperechoic rings around renal pyramids, increased cortex echogenicity); and in the other five TWs, there were no abnormalities in laboratory tests or on sonographic examination, although one of the five TWs had mean systolic blood pressure (SBP) and mean diastolic blood pressure (DBP) over the $95^{\text {th }}$ percentile, and one TWs had SBP over the $95^{\text {th }}$ percentile.

Urinalysis with urine sediment assessment

We observed no abnormalities in the urine sediments. 


\section{Kidney Blood Pressure Research}

Renal injury and Chronic Kidney Disease

CKD in TWs might be a consequence of nephrectomy. Six TWs $(11,3 \%)$ had eGFR of 60 $89 \mathrm{ml} / \mathrm{min} / 1,73 \mathrm{~m}^{2}$. These individuals could be classified as G2 category if confirmed after three months.

Of the patients with eGFR $\geq 90 \mathrm{ml} / \mathrm{min} / 1,73 \mathrm{~m}^{2}$, no abnormalities (neither on sonographic examination nor in laboratory tests) were found in 26 TWs, while 21 TWs had sonographic or laboratory signs of kidney damage. Fifteen of these twenty-one TWs had abnormalities on sonographic examination: in eight cases, hyperechoic rings around renal pyramids were the only abnormalities diagnosed. None of these TWs underwent potentially nephrotoxic chemotherapy or irradiation. Five out of twenty-one TWs had increased albumin excretion with no signs of kidney damage on ultrasound examination. One TWs had increased albumin excretion (ACR - 148, $9 \mathrm{mg} / \mathrm{dl}$ ) and abnormalities on sonographic examination (increased cortex echogenicity, hyperechoic rings around renal pyramids).

Five out of six TWs at risk for stage II of CKD had signs of kidney damage on ultrasound examination. One of those five individuals also had increased albumin excretion. One out of six TWs at risk for stage II of CKD had decreased eGFR (60-89 ml/min/1, $\left.73 \mathrm{~m}^{2}\right)$ with no abnormality on sonographic examination and with no increased albumin secretion.

\section{Blood Pressure}

In the TWs group, mean SBP $>95^{\text {th }}$ percentile and DBP $>95^{\text {th }}$ percentile were in seven individuals $(13,2 \%)$. Another five individuals $(9,4 \%)$ had values of mean SBP over the $95^{\text {th }}$ percentile. In one case $(1,9 \%)$, the mean values of SBP and DBP were between the $90^{\text {th }}$ and $95^{\text {th }}$ percentiles. None of the individuals in the control group had arterial hypertension. Ten individuals $(22,7 \%)$ in the control group had mean values of SBP and DBP between the $90^{\text {th }}$ and $95^{\text {th }}$ percentiles.

The treatment of TW was performed according to the following protocols: SIOP 9-4 individuals; SIOP 1993-30 individuals; and SIOP 2001-19 individuals. Eight TWs were treated with potentially nephrotoxic chemotherapeutic agents (carboplatin, cisplatin, ifosphamide, cyclophosphamide). There were no significant differences in terms of sonographic parameters or eGFR between TWs who received and did not receive potentially nephrotoxic chemotherapeutic agents. Those two groups did not differ in terms of age, height and weight. Among 21 TWs with signs of kidney damage, there were four individuals who received potentially nephrotoxic chemotherapeutic agents. In the other four TWs who received potentially nephrotoxic chemotherapeutic agents, signs of kidney damage on sonographic examination were not observed.

Radiation therapy was performed during treatment of 22 TWs $(41,5 \%)$. In four cases, the solitary kidney was in the field of irradiation. The dose of irradiation did not exceed 20 Gy. Two of these four individuals also received potentially nephrotoxic chemotherapeutic agents.

\section{Discussion}

Individuals with a solitary kidney are a specific group of patients. In recent years, there has been an ongoing discussion about kidney damage in patients with SFK $[23,24,25,26]$. According to Schreuder's study, being born with or having an acquiring SFK in childhood results in ongoing glomerular hyperfiltration and in renal injury with hypertension and albuminuria before adulthood in over $50 \%$ of those affected [23]. On the other hand, P. Marzuillo and C. Polito evaluated a cohort of 306 congenital SFK patients with prenatal diagnosis and enrollment within the first 3 months of life, and showed that the prevalence of renal damage was 3, 9\%, with a cumulative proportion of $93,7 \%$ free from renal injury at 17 years of age [24]. But, as Schreuder emphasized, both cohorts were different - in the Marzuillo and Polito's study all children were diagnosed antenatally or shortly after birth, 


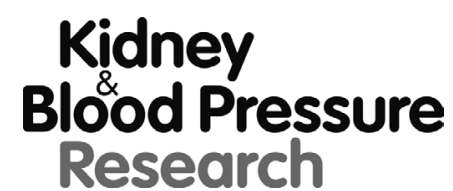

\begin{tabular}{l|l}
\hline Kidney Blood Press Res 2018;43:1363-1374 \\
\hline DOI: 10.1159/000492951 & $\begin{array}{l}\text { (c) 2018 The Author(s). Published by S. Karger AG, Basel } \\
\text { www.karger.com/kbr }\end{array}$ \\
\hline Published online: 27 August, 2018 &
\end{tabular}

whereas in Schreuder's study the congenital SFK was diagnosed later in life. Both groups differed in prevalence of high blood pressure, which was present in $0,6 \%$ of the Marzuillo's cohort and in 18, 1\% in Schreuder's study [26].

Most of the patients who have been cured from TW have one kidney and they seem to be particularly at risk of kidney damage because of their exposition to additional risk factors, such as anticancer treatment. However, the typical chemo-and radiotherapy used in TW treatment does not generally cause severe renal injury [8,27]. According to SIOP rules, only high-risk patients or in stage IV are treated with nephrotoxic cytostatics, such as carboplatin and cyclophosphamide [3]. Bilateral TWs are also at higher risk of CKD [8].

Then the assessment of SFK in TWs is very important. The follow-up of TWs includes physical examination with measurement of BP, abdomen ultrasound, and a serum creatinine and urine test [3].

Hyperechoic rings around renal pyramids on sonographic examination, observed in $41,5 \%$ of TWs, may indicate impairment of renal tubules. Hyperechoic rings around renal pyramids might be the outcome of one of the following: primary hypercalciuria, hypercalcemia with hypercalciuria, hyperparathyroidism, or tubular acidosis $[28,29,30]$. Hyperechoic rings around renal pyramids are the outcome of the accumulation of calcium deposit in the distal and collecting tubules [31]. According to the theory of AndersonCarr, hyperechoic rings around renal pyramids appear initially before formation of renal calculi [32]. Hyperechoic rings may be an ultrasound sign of early nephrocalcinosis [33, 34]. In all TWs with hyperechoic rings around renal pyramids, further diagnosis focusing on tubular impairment is necessary. The mean values of RI in TWs didn't exceed normal values. Hyperechoic rings around renal pyramides might even precede modification in the parenchymal microvasculature due to normal values of RI.

In our sample increased cortex echogenicity was observed in six TWs $(11,3 \%)$. This is a nonspecific sonographic marker of acute and chronic changes in glomeruli or renal parenchyma $[35,36]$. Cortex echogenicity correlated with histological changes in renal parenchyma and with tubular atrophy $[37,38]$.

Renal scars were more common in TWs $(4-7,5 \%)$. There were no scars observed in the control group (no statistical significance). The presence of these signs may be an outcome of urinary tract infection during immunosuppression. Renal scars appear directly over calyces and are associated with parenchymal thickening [39].

Renal calculi were detected in 3 TWs $(5,6 \%)$. None of the individuals in the control group had renal calculi diagnosed. In two cases, time from the end of treatment was relatively short - four and ten months. Renal calculi might be a consequence of chemotherapy. According to Palmer et al., the sensitivity of ultrasound examination for detection of renal calculi was $89 \%$ in comparison to that for computed tomography, which was $100 \%$ [40]. Thus, the true prevalence of nephrolithiasis might be more frequent than that presented in this study.

In the present study, hypertrophy of the solitary kidney was observed in thirty-eight (71, 7\%) TWs. In an English study, Bailey reported compensatory renal hypertrophy in 38/40 patients [41]. Neu et al. detected compensatory contralateral renal hypertrophy in $88,3 \%$ of TWs [42]. The mean percent of expected renal length in the TWs group was $118 \%$, while in the control group, the value of expected renal length was nearly $100 \%$. In a study by $\mathrm{Di}$ Tullio et al., the mean length of the solitary kidney was $128 \%$ of the reference value [9]. The study was repeated after six years, and there were no significant differences in length and volume of the kidney [10]. Similar values were observed by Krawczuk-Rybak et al. [12]. In a study by Levitt et al., hypertrophy of the solitary kidney was observed in $55 \%$ of individuals [11]. Zerin et al. observed hypertrophy of the solitary kidney in $50 \%$ of TWs [13]. Kishore reported compensatory hypertrophy in 8/29 TWs and subnormal renal size in one TWs [43].

In TWs, mean eGFR was significantly lower than that of the control group. Six TWs (11, $3 \%$ ) had eGFR below $90 \mathrm{ml} / \mathrm{min} / 1,73 \mathrm{~m}^{2}$. Di Tullio et al. and Indolfi et al. did not observe decreased eGFR, as assessed with the Schwartz formula $[9,10]$. These results are similar to findings of Srinivas et al. and Chevallier et al., who did not observe decreased eGFR, measured 


\section{Kidney Blood Pressure Research}

with inulin clearance $[14,44]$. In study by Levitt et al., GFR below $80 \mathrm{ml} / \mathrm{min} / 1,73 \mathrm{~m}^{2}$, measured as $51 \mathrm{Cr}$ EDTA clearance, was detected in 19\% of cases [11]. Decreased GFR below $80 \mathrm{ml} / \mathrm{min} / 1,73 \mathrm{~m}^{2}$ was also observed in $43 \%$ individuals, according to Krawczuk-Rybak et al. [12]. By contrast, increased GFR was reported by Stronska et al. and Donckerwolck et al. $[45,46]$. Cozzi reported that TWs aged 33 to 51 years showed significantly progressive decrease in eGFR (mean \pm SD $88,1 \pm 22,6$ during the third decade after surgery vs. $66,6 \pm 15$, $6 \mathrm{ml} / \mathrm{min} / 1,73 \mathrm{~m}^{2}$ during the fifth decade after surgery, $\mathrm{p}=0$, 02) [47]. According to Kern, longer follow-up may reveal clinically significant declines in renal function occurring years following nephrectomy [48].

In the present study, increased albumin excretion, measured as ACR over $30 \mathrm{mg} / \mathrm{g}$, was observed in 13, $2 \%$ of TWs. Prevalence of albuminuria in the published literature ranges from $9 \%$ (Levitt et al.) to $84 \%$ (Srinivas et al.) $[9,10,11,14,44]$.

In the present study, there was no correlation between the percent of expected renal length and sonographic and laboratory parameters. In a study by Di Tullio, the length of the solitary kidney inversely correlated with age at time of diagnosis, and kidney volume directly correlated with microalbuminuria [9]. Levitt did not observe a correlation of renal length with eGFR, microalbuminuria, SBP or treatment of TW [11]. There were no correlations between sonographic findings and laboratory tests in a study by Krawczuk-Rybak et al. [12]. Zerin did not observe a correlation between the prevalence of renal hypertrophy and age at time of nephrectomy, stage of tumour or treatment of TW [13].

This study analysed the risk of CKD in TWs. Nephrectomy was one of the risk factors for CKD in TWs. Six TWs might be classified as stage II of CKD. According to Stefanowicz et al., 56, $25 \%$ and $43,75 \%$ of TWs were diagnosed as stage I and II of CKD, respectively [16]. However, according to Interiano et al., the current guidelines do not recognize solitary kidney as a structural abnormality [49]. However, further studies are needed to determine whether the absence of one kidney is a marker for CKD development [49]. In the Neu TWs study, 21/34 (62\%) TWs (mean age 28.7 years, mean follow-up 24.8 years) had CKD stages I-III, based on cystatin-related eGFR [42]. The reason for those differences was the method of GFR estimation. In the present study, classification was based on estimated GFR, while in the study by Stefanowicz et al., GFR was assessed as clearance of 99 Tc-DTPA [16]. Classification of CDK underlines the risk of deterioration of renal function. The end stage of renal disease twenty years after the treatment for Wilms tumour is rather low: 0,6\%, according to Breslow et al. [50].

There were differences in the sonographic and laboratory parameters between TWs who received and did not receive potentially nephrotoxic chemotherapeutic agents (carboplatin, cisplatin, ifosphamide, or cyclophosphamide). Potentially nephrotoxic chemotherapeutic agents were administered for high risk histology and stages III and IV of TW. There were no differences in the distribution of stage of TW between individuals with and without sonographic signs of kidney damage. These findings can be explained by the fact that according to SIOP guidelines, cisplatin was exchanged for the potentially less nephrotoxic carboplatin, and ifosphamide was exchanged for the less nephrotoxic cyclophosphamide. Additionally, according to SIOP 2001, carboplatin is administered in six cycles. Each cycle lasts for three days with a daily dose of $200 \mathrm{mg} / \mathrm{m}^{2}$ [3]. Previously, carboplatin was administered one day with a dose of $600 \mathrm{mg} / \mathrm{m}^{2}$.

Radiation therapy in the field of the solitary kidney was performed in four TWs (7, $5 \%$ ) enrolled in our study. Two of these TWs additionally received potentially nephrotoxic chemotherapy. Those individuals were treated according to the SIOP 93-01 and SIOP 9 protocols. In the present study, sonographic and laboratory parameters were not compared among groups who received and did not receive irradiation to the field of the solitary kidney because of disproportion in groups - 4 vs 49. De Graff et al. observed lower values of GFR and renal plasma flow (RPF) in TWs who underwent irradiation in comparison to those who did not undergo irradiation of the solitary kidney [51]. 


\section{Kidney \\ Blood Pressure Research}

Hypertension may be an early indicator of renal dysfunction in TWs. The prevalence of arterial hypertension was diagnosed in six TWs $(11,3 \%)$. None of the individuals in the control group had arterial hypertension diagnosed. None of the individuals enrolled in the study had antihypertensive drugs administered. According to other authors, the prevalence of hypertension in TWs was $11-29 \%[11,52]$. In the Neu study, $40 \%$ of TWs had arterial hypertension [42]. Arterial hypertension is not a diagnostic criterion of CKD, but it can increase the risk of deterioration of eGFR and cardiovascular complications [6]. Lubrano et al. showed that patients with acquired SFK due to previous monolateral total nephrectomy due to trauma over a 14-year follow-up had significant increases in hypertension $(12 \%$ vs $52,9 \%$ ) [53]. In view of this fact, it is necessary to monitor BP every six months. Some authors recommended BP monitoring at least every five years [54], but in our opinion, this is too infrequent.

Is solitary kidney a risk factor for renal injury or chronic kidney disease? We believe this is an open question. Although current NKF guidelines do not recognize SFK as a structural abnormality [6], several studies suggest that SFK is a risk factor for the progression of CKD $[44,55,56]$. Kolvek et al. demonstrated that a substantial proportion of children with SFK developed renal injury defined as hypertension, severely increased albuminuria and a significantly impaired eGFR and/or use of antihypertensive or antiproteinuric medications during childhood (median age 11,0 years). This was especially true for those with CAKUT (congenital anomalies of the kidney and the urinary tract) in the SFK [57]. MavinkurveGroothuls et al. showed that during follow-up, mean eGFR and BP z-scores remained stable at an acceptable level, but in the group of 31 TWs with follow-up of 15 years, only $23 \%$ showed signs of renal injury (defined as eGFR $<60 \mathrm{ml} / \mathrm{min} / 1,73 \mathrm{~m}^{2}$, proteinuria and/or high BP, and/or drug use to treat either proteinuria and/or high BP) vs $54 \%$ in a group of SFK patients based on non-oncological causes $(p=0,0004)$ [58]. According to KDIGO recommendations, CKD is defined as abnormalities of kidney structure or function, present for $>3$ months with implications for health. CKD is classified based on cause, GFR category (G1-G5), and albuminuria category (A1-A3), abbreviated CGA [6]. In our group of TWs, six $\left(11,3 \%\right.$ ) had values of eGFR below $90 \mathrm{ml} / \mathrm{min} / 1,73 \mathrm{~m}^{2}-\mathrm{G} 2$ category. Increased albumin urine excretion (ACR $>30 \mathrm{mg} / \mathrm{g}$ ) was observed in 7 TWs $(13,2 \%), 6$ in the A2 category and 1 in the A3 category, risk category: G1A2 (moderately increased risk) - 6, G2A2 (high risk) -1. Schiavetti et al. examined 35 TWs and diagnosed CKD in 3 TWs, of G2A2 category (1) and G1A2 category (2), and detected signs of kidney damage on USG in 1 TWs [59].

The limitations of this study are as follows: 1. Colorimetric-modified Jaffe method of creatinine serum concentration measurement: this factor influenced the choice of formulas to calculate eGFR, according to KDOQI guidelines. 2. Heterogeneity of the TWs group: children with differences in stages and histology. These conditions have an influence on the type of treatment (chemo- and/or no radiotherapy) that might be an additional factor for kidney damage. 3. Controls were patients with both kidneys.

\section{Conclusion}

Ultrasonographic abnormalities in solitary kidneys of TWs are frequent. The most frequently detected anomalies in SFK in TWs are hyperechoic rings around renal pyramids. In TWs sonographic examination is ought to be performed, not only to diagnose tumour recurrence and to assess hypertrophy, but also to assess the signs of kidney damage and their progression. 


\section{Kidney \\ Blood Pressure Research}

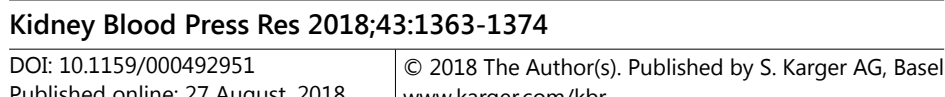

Published online: 27 August, 2018

www.karger.com/kbr

Kosiak et al:: Sonographic Image of Solitary Kidney in TWs

Disclosure Statement

No conflicts of interest, financial or otherwise are declared by the authors.

\section{References}

$>1$ Kaste SC, Dome JS, Babyn PS, Graf NM, Grundy P, Godzinski J, Levitt GA, Jenkinson H: Wilms tumour: prognostic factors, staging, therapy and late effects. Pediatr Radiol 2008;38:2-17.

2 Fernandez CV, Geller JI, Ehrilch PF, Hill DA, Kalapurakal JA, Dome JS: Renal tumors; in Pizzo PA, Poplack DG (eds): Principles and Practice of Pediatric Oncology. Philadelphia, Baltimore, New York, London, Buenos Aires. Hong Kong, Sydney, Tokyo, Wolters Kluwer, 2016, pp 753-771.

3 SIOP: Recommendations for longterm follow-up of children with renal neoplasms. Nephroblastoma Clinical Trial and Study Protocol, 2001;Appendix 7:161-162. URL: https://www.skion.nl/workspace/uploads/ Protocol-SIOP-2001.pdf.

4 Brisse HJ, Smets AM, Kaste SC, Owens CM: Imaging in unilateral Wilms tumour. Pediatr Radiol 2008;38:1829.

5 National Kidney Foundation K/DOQI: URL: https://www.kidney.org/sites/default/files/docs/ckd_ evaulation_classification_stratification.pdf

6 KDIGO: 2012 Clinical Practice Guideline for the Evaluation and Management of Chronic Kidney Disease. URL: http://www.kdigo.org/clinical_practice_guidelines/pdf/CKD/KDIGO_2012_CKD_GL.pdf.

7 Bardi E, Olah AV, Bartyik K, Endreffy E, Jenei C, Kappelmayer J, Kiss C: Late effects on renal glomerular and tubular function in childhood cancer survivors. Pediatr Blood Cancer 2004;43:668-673.

8 Stefanowicz J, Kosiak M, Kosiak W, Lipska-Ziękiewicz B: Chronic kidney disease in Wilms tumour survivors - what do we know today?; in Van del Heuvel-Eibrink MM (ed): Wilms tumor Australia, Codon Publications, 2016, pp 131-145.

-9 Di Tullio MT, Casale F, Indolfi P, Polito C, Giuliano M, Martini A, Cimmaruta E, Morgera C, Cioce F, Greco N: Compensatory hypertrophy and progressive renal damage in children nephrectomized for Wilms tumor. Med Pediatr Oncol 1996;26:325-328.

10 Indolfi P, Di Tulio MT, Casale F, De Rosa E, Polito C, Cioce F: Letter to the Editor: Kidney Size and Function After Unilateral Nephrectomy for Wilms Tumor: A Longitudinal Study. Med Pediatr Oncol 2001;37:485-486.

11 Levitt GA, Yeomans E, Dicks Mircaux C, Breatnach F, Kingston J, Pritchard J: Renal size and function after cure of Wilms tumor. Br J Cancer 1992;66:877-882.

12 Krawczuk-Rybak M, Kuźmicz M, Kitszel A, Wysocka J, Zalewska B, Olszewska M: Renal function and size after complex treatment of Wilms' tumour. Med Wieku Rozwoj. 2003;7:359-367.

13 Zerin JM, Haliloglu M, Cohen MD: Growth of the solitary kidney after nephrectomy in children with unilateral Wilms tumor. Pediatr Radiol 1996;26:547-552.

14 Srinivas M, Agarwala S, Padhy AK, Gupta AK, Bajpai M, Bhatnagar V, Gupta DK, Mitra DK: Somatic growth and renal function after unilateral nephrectomy for Wilms' tumor. Pediatr Surg Int 1998;14:185-188.

-15 Stefanowicz J, Kosiak M, Kosiak W, Korbus-Kosiak A, Sierota D, Owczuk R: Cystatin C and parenchymal thickness/kidney length ratio in Wilms tumor survivors. Pediatr Blood Cancer 2010;54:41-46.

-16 Stefanowicz J, Kosiak M, Romanowicz G, Owczuk R, Adamkiewicz-Drożyńska E, Balcerska A: Glomerular filtration rate and prevalence of chronic kidney disease in Wilms' tumour survivors. Pediatr Nephrol 2011;26:759-766.

$>17$ Chen JJ, Pugach J, Patel M, Luisiri A, Steinhardt GF: The renal length nomogram: a multivariable approach. J Urol 2002;168:2149-2152.

18 MrNomogram: Multivariable Pediatric Renal Nomogram. URL: https://www.prevmed.sunysb.edu/jjc/ MrNomogram/Default.aspx.

19 Schwartz GJ, Haycock GB, Edelmann CM Jr, Spitzer A: A simple estimate of glomerular filtration rate in children derived from body length and plasma creatinine. Pediatrics 1976;58:259-263.

20 Walser M: Assessing renal function from creatinine measurements in adults with chronic renal failure. Am J Kidney Dis 1998;32:23-31. 


\section{Kidney \\ Blood Pressure Research}

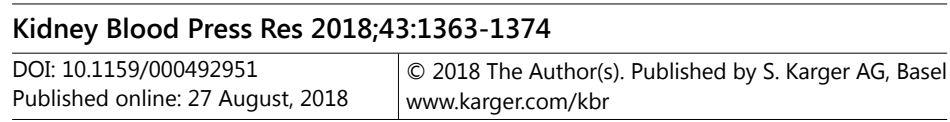

Kosiak et al.: Sonographic Image of Solitary Kidney in TWs

-21 Keane WF, Eknoyan G: Proteinuria, albuminuria, risk assessment, detection, elimination (PARADE): a position paper of the National Foundation. Am J Kidney Dis 1999;33:1004-1010.

-22 National High Blood Pressure Education Program Working Group on High Blood Pressure in Children and Adolescents: The fourth report on the diagnosis, evaluation and treatment of high blood pressure in children and adolescents. Pediatrics 2004;114:555-576.

23 Schreuder MF: Life with one kidney. Pediatr Nephrol 2018;33:595-604.

24 Marzuillo P, Guarino S, Grandone A, Di Somma A, Della Vecchia N, Esposito T, Macchini G, Marotta R, Apicella A, Diplomatico M, Rambaldi PF, Perrone R, Miraglia del Giudice E, La Manna A, Polito C: Outcomes of a cohort of prenatally diagnosed and early enrolled patients with congenital solitary functioning kidney. J Urol 2017;198:1153-1158.

25 Marzuillo P, Polito C: Congenital solitary kidney in childhood: not so bad. Pediatr Nephrol 2018;33:723724.

26 Schreuder MF: Life with one kidney: response to comments by Marzuillo and Polito. Pediatr Nephrol 2018;33:725-726.

27 Skinner R: Late renal toxicity of treatment for childhood malignancy: risk factors, long-term outcomes, and surveillance. Pediatr Nephrol 2018;33:215-225.

28 Hernanz-Schulman M: Hyperechoic renal medullary pyramids in infants and children. Radiology 1991;181:9-11.

29 Jequier S, Kaplan BS: Echogenic renal pyramids in children. J Clin Ultrasound 1991;19:85-92.

30 Shultz PK, Strife JL, Strife CF, McDaniel JD: Hyperechoic renal medullary pyramids in infants and children. Radiology 1991;181:163-167.

31 Saarela T, Lanning P, Koivisto M: Prematurity-associated nephrocalcinosis and kidney function in early childhood. Pediatr Nephrol 1999;13:886-890.

32 Paivansalo MJ, Kallioinen MJ, Merikanto JS, Jalovaara PK: Hyperechogenic „rings” in the periphery of renal medullary pyramids as a sign of renal disease. J Clin Ultrasound 1991;19:283-287.

33 Al-Murrani B, Cosgrove DO, Svensson WE, Blaszczyk M: Echogenic rings - an ultrasound sign of early nephrocalcinosis. Clin Radiol. 1991;44:49-51.

34 Shavit L, Jaeger P, Unwin RJ: What is nephrocalcinosis? Kidney Int 2015;88:35-43.

35 Huntington DK, Hill SC, Hill MC: Sonographic manifestation of medical renal disease. Semin Ultrasound CT MR. 1991;12:290-307.

-36 Hricack H, Cruz C, Romanski R, Uniewski MH, Levin NW, Madrazo BL, Sandler MA, Eyler WR: Renal parenchymal disease: sonographic-histologic correlation. Radiology 1982;144:141-147.

-37 Rosenfield AT, Siegel NJ: Renal parenchymal disease: histopathologic-sonographic correlation. AJR Am J Roentgenol 1981;137:793-798.

-38 Quaia E, Bertolotto M: Renal parenchymal disease: is characterization feasible with ultrasound? Eur Radiol 2002;12:2006-2020.

39 Chu WCW: Renal Junction Line; in Ahuja AT (ed): Diagnostic Imaging: Ultrasound. Salt Lake City, Utah, Amirsys, 2007, chapter 5, pp 9.

40 Palmer JS, Donaher ER, O'Riordan MA, Dell KM: Diagnosis of pediatric urolithiasis: role of ultrasound and computerized tomography. J Urol 2005;174:1413-1416.

-41 Bailey S, Roberts A, Brock C, Price L, Craft AW, Kilkarni R, Lee RE, Skillen AW, Skinner R: Nephrotoxicity in survivors of Wilms' tumours in the North of England. Br J Cancer 2002;87:1092-1098.

42 Neu MA, Russo A, Wingerter A, Alt F, Theruvath J, El Malki K, Kron B, Dittrich M, Lotz J, Stein R, Beetz R, Faber J: Prospective analysis of long-term renal function in survivors of childhood Wilms tumor. Pediatr Nephrol. 2017;32:1915-1925.

43 Kishore SS, Oberoi S, Bhattacharya A, Prasad R, Trehan A, Bansal D, Marwaha RK: Function and size of the residual kidney after treatment of Wilms tumor. Pediatr Hematol Oncol 2015;32:11-17.

\$4 Chevallier C, Hadj-Aissa A, Brunat-Mentigny M, Faraj G, Schell M, Cochat P: Renal function after nephrectomy for Wilms' tumor. Arch Pediatr 1997;7:639-644.

45 Strońska E, Zwolińska D, Sawicz-Birkowska K, Makulska I, Magier K, Czernik J: Assessment of function of the only kidney in children after nephrectomy due to Wilms' tumour. Pol Merkur Lekarski 2003;14:311314. 


\section{Kidney \\ Blood Pressure Research}

46 Donckerwolcke RM, Coppes MJ: Adaptation of renal function after unilateral nephrectomy in children with renal tumors. Pediatr Nephrol 2001;16:568-574.

47 Cozzi DA, Ceccanti S, Cozzi F: Renal function up to the $5^{\text {th }}$ decade of live after nephrectomy in childhood: a literature review. Nephrology (Carlton) 2018;23:397-404.

-48 Kern AJ, Inouve B, Ko JS, Gorin MA, Allaf ME, Goldstein S, DiCarlo HN, Shah BB, Wang MH: Impact of nephrectomy on long-term renal function in non-syndromic children treated for unifocal Wilms tumor. J Pediatr Urol 2014;10:662-666.

-49 Interiano RB, Delos-Santos N, Huang S, Srivastava DK, Robinson LL, Hudson MM, Green DM, Davidoff AM: Renal function in survivors of nonsyndromic Wilms tumor treated with unilateral radical nephrectomy. Cancer 2015;121:2449-2456.

$>50$ Breslow NE, Collins AJ, Ritchey M L Grigoriev YA, Peterson SM, Green DM: End stage renal disease in patients with Wilms tumor: results from the National Wilms Tumor Study Group and the United States Renal Data System. J Urol 2005;174:1972-1975.

51 de Graaf SS, van Gent H, Reitsma-Bierenes WC, van Luyk WH, Dolsma WV, Postma A: Renal function after unilateral nephrectomy for Wilms tumor: the influence of radiation therapy. Eur J Cancer 1996:32A:465469.

52 Barrera M, Roy LP, Stevens M: Long-term follow-up after unilateral nephrectomy and radiotherapy for Wilms' tumour. Pediatr Nephrol 1989;3:430-432.

53 Lubrano R, Gentile I, Falsaperla R, Vitaliti G, Marcellino A, Elli M: Evolution of blood pressure in children with congenital and acquired solitary functioning kidney. Ital J Pediatr 2017;43:43.

54 Spreafico F, Terenziani M, Testa S, Perotti D, Collini P, Piva L, Ardissino G: Long-term renal outcome in adolescent and young adult patients nephrectomized for unilateral Wilms tumor. Letter to the Editor. Pediatr Blood Cancer 2014;61:1136-1137.

55 Cozzi DA, Ceccanti S, Frediani S, Schiavetti A, Cozzi F: Chronic kidney disease in children with unilateral renal tumor. J Urol. 2012;187:1800-1805.

-56 Cozzi DA, Ceccanti S, Frediani S, Mele E, Cozzi F: Renal function adaption up to fifth decade after treatment of children with unilateral renal tumor: a cross sectional and longitudinal study. Pediatr Blood Cancer 2013;60:1534-1538.

57 Kolvek G, Podracka L, Rosenberger J, Stewart RE, van Dijk JP, Reijnveld SA: Solitary functioning kidney in children - a follow up study. Kidney Blood Press Res 2014;39:272-278.

58 Mavinkurve-Groothuis AM, van de Kracht F, Westland R, van Wijk JA, Loonen JJ, Screuder MF: Long-term follow-up of blood-pressure and glomerular filtration rate in patients with a solitary functioning kidney: a comparison between Wilms tumor survivors and nephrectomy for other reasons. Pediatr Nephrol 2016;31:435-441.

59 Schiavetti A, Altavista P, De Luca L, Andreoli G, Megaro G, Versacci P: Long-term renal function in unilateral non-syndromic renal tumor survivors treated according to International Society of Pediatric Oncology Protocols. Pediatr Blood Cancer 2015;62:1637-1644. 